\title{
Power Quality Enhancement in Grid Connected PV Systems using High Step up DC-DC Converter
}

\author{
V S Prasadarao K ${ }^{1}$, K V Krishna Rao ${ }^{2}$, P Bala Koteswara Rao ${ }^{3}$, T Abishai ${ }^{4}$ \\ ${ }_{1,4}$ Departement of Electrical and Electronics Engineering, KL University, India \\ ${ }^{2}$ Departement of Electrical and Computer Engineering, JIGJIGA University, India \\ ${ }^{3}$ Departement of Electrical and Electronics Engineering, Gudlavalleru Engineering College, India
}

\begin{tabular}{l} 
Article Info \\
\hline Article history: \\
Received Apr 23, 2016 \\
Revised Mar 9, 2017 \\
Accepted Mar 23, 2017 \\
\hline Keyword: \\
Distributed generation (DG) \\
Photo voltaic (PV) \\
Power quality (PQ) \\
Renewable energy sources \\
(RES). \\
shunt active power filter \\
(SAPF)
\end{tabular}

(SAPF)

\begin{abstract}
Renewable energy sources (RES) are gaining more importance in the present scenario due to the depletion of fossil fuels and increasing power demand. Solar energy is the one of the most promising as it is clean and easily available source. The voltage obtained from the PV system is low. This voltage is increased by high step up dc-dc converter which uses only one switch leads to low switching losses and hence the efficiency of this converter is high. To get the good response this converter is operated in closed loop manner. Integration of PV system with existing grid has so many issues like distorted voltage, current and reactive power control etc. This paper presents a four leg inverter which works on hysteresis current control technique to address the power quality issues like reactive power compensation, balanced load currents and compensation of neutral current. The switching to the inverter is designed in such a way that it supplies the extra current to stabilise the current of the grid that is being supplied to the loads. Finally, the proposed technique is validated by using mat lab/Simulink software and corresponding results are presented in this paper.
\end{abstract}

Copyright $(2017$ Institute of Advanced Engineering and Science. All rights reserved.

\section{Corresponding Author:}

V S Prasadarao K,

Departement of Electrical and Electrical Engineering,

K L University,

Vaddeswaram, Guntur (dt), A.P - India

Email: kvsprasad86@gmail.com

\section{INTRODUCTION}

Now-a-days there is more demand in renewable energy generating systems. Electric devices and power consumers are increasing abruptly and mainly concerned in reaching this high energy demand. Nearly seventy percent of whole electric energy requirement is being generated by the burning of fossil fuels. But increase in air pollution causing various problems like global warming effect, depletion of fossil fuels, their increase in cost etc., have madeto look forward for renewable sources as the solution for future power demand. For this reason, solar energy has more demand as it is a clean and easily available source. To meet the load demand, incorporation of RES [1] is one of the suitable solution called Distributed Generation (DG). The loads are fretful due to the instabilitynature of RES in distribution systems as they cause the risk of network stability, poor voltage regulation (VR) and PQ problems. Therefore, the DG [2-4] systems should comply standards ensure its safety, to increase reliability and efficient operation. The advancement in the technology of converters and control strategies makes DG system controlled [5-7], actively to enhance the system performances by improving PQ at Point of common Coupling (PCC). Moreover, usage of power electronics (PE) devices, non-linear loads generate harmonics related to currentswhich leads to quality issues in the power generation. Commonly, VSI with current control are preferred to interface with unstable natured RES of DG. Recently, there are many control techniques are used. In [5] an inverter operates like active inductor reducing the harmonic related to current. Active power filters (APF) [8] being extensively used for 
the compensation of the harmonics of current and load unbalance from distribution level. This results extra cost for hardware. However, we united the properties of APF of conventional inverter combining of renewable to the grid, without extra cost. The power obtained from PV cell is low. In this paper PV system is integrated to the existing grid with four leg inverter. The functions performed by the four leg inverter are as follows: 1.It controls the power exchanged between grid and RES 2. It can compensate the neutral current and reduces the distortion in the load current. The input for the four leg inverter is a dc source (ie.PV system). The low voltage obtained from the PV system is enhanced by the high step up dc-dc converter [9]. This converter increases the input voltage by 13 percent with use of one switch only. So, the switching losses are low and hence the efficiency is high. To get the faster response the presented dc-dc converter is implemented in closed loop manner by proper tuning of PI controller.

\section{HIGH STEP UP DC-DC CONVERTER}

The Figure 1 shown below is the circuit diagram of the proposedhigh step up dc-dc converter. It helps is stepping up the low rated voltage rating that is obtained from the PV system to the suitable grid voltage and the features of it are as follows, 1. The connection between coupled inductors, capacitor, and diode helps in attaining a large step-up voltage ratio. 2. The energy stored in coupled inductor can be recycled, which helps in increasing the efficiency, and maintaining the voltage stress across the active switch S1. 3. The switch $\mathrm{S} 1$ helps in separating the PV panel energy during non-operating conditions efficiently, this helps in enhancing the safety of the system.

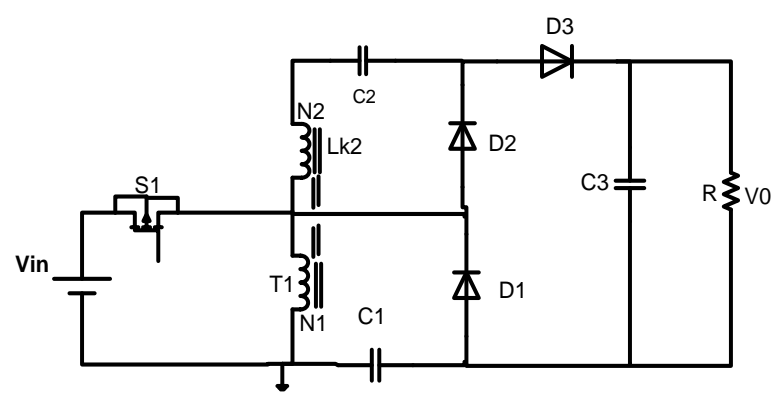

Figure 1. Proposed High Step up DC-DC Converter

The high step up dc-dc converter is operated in five modes as follows

1) Mode 1 $\left[\mathbf{t}_{0}, \mathbf{t}_{1}\right]$ : In this mode, when $S_{1}$ is in $\mathrm{ON}$ position the magnetizing inductor $\mathrm{L}_{\mathrm{m}}$ charges the capacitor $\mathrm{C}_{2}$ continuously through linear transformer $\mathrm{T} 1$. The current flow path is shown in Figure 2 below when the switch $S_{1}$ and diode $D_{2}$ are conducting. The accepted $i_{\text {Lm }}$ is small because the antecedent voltage $\mathrm{V}_{\text {in }}$ crossing the primary arising magnetizing inductor $\mathrm{L}_{\mathrm{k} 1}$ and magnetizing inductor $\mathrm{L}_{\mathrm{m}}$ is still appointment its activity through accompanying inductor $\mathrm{T}_{1}$ to allegation switched capacitor $\mathrm{C}_{2}$, but the energy is slightly decreasing. The charging currents $\mathrm{i}_{\mathrm{D} 2}$ and $\mathrm{i}_{\mathrm{C} 2}$ through $\mathrm{D} 2$ and $\mathrm{C} 2$ are decreasing.

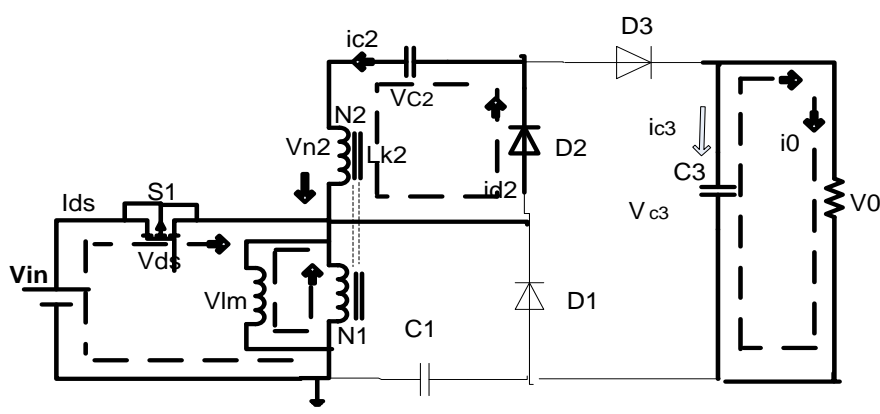

Figure 2. Circuit diagram for mode1 operation 
2) Mode $2\left[\mathbf{t}_{1}, \mathbf{t}_{2}\right]$ : In this mode, the source $\mathrm{V}_{\text {in }}$ is connected serially with N2, C1, and capacitor $\mathrm{C} 2$ to the output charge capacitor $\mathrm{C}_{3}$ and load $\mathrm{R}$. At the same timethe magnetizing inductor $\mathrm{L}_{\mathrm{m}}$ is also receiving energy from $V_{\text {in. }}$. The current flow path is shown in Figure 3 when the switch $\mathrm{S}_{1}$ remained in ON position, the diode $\mathrm{D}_{3}$ is conducting. The currents $i_{L m}, i_{L K 1}$, and $i_{D 3}$ are accretion because the $V_{\text {in }}$ is across $\mathrm{L}_{\mathrm{K} 1}, \mathrm{~L}_{\mathrm{m}}$, and primary winding of inductor $\mathrm{N}_{1}, \mathrm{~L}_{\mathrm{m}}$ and $\mathrm{L}_{\mathrm{K} 1}$ are storing energy from the source Vin, at the same time $V_{\text {in }}$ is also serially connected with secondary winding $\mathrm{N}_{2}$ of coupled inductor $\mathrm{T}_{1}$, capacitors $C_{1}$, and $C_{2}$, and again discharges their stored energy to capacitor $C_{3}$ and load $R$. The currents $\mathrm{i}_{\mathrm{in}}, \mathrm{i}_{\mathrm{D} 3}$ and are discharging as the currents $\mathrm{i}_{\mathrm{C} 1}$ and $\mathrm{i}_{\mathrm{C} 2}$ are increasing. The process ends if the switch is OFF at $\mathrm{t}=\mathrm{t}_{2}$.

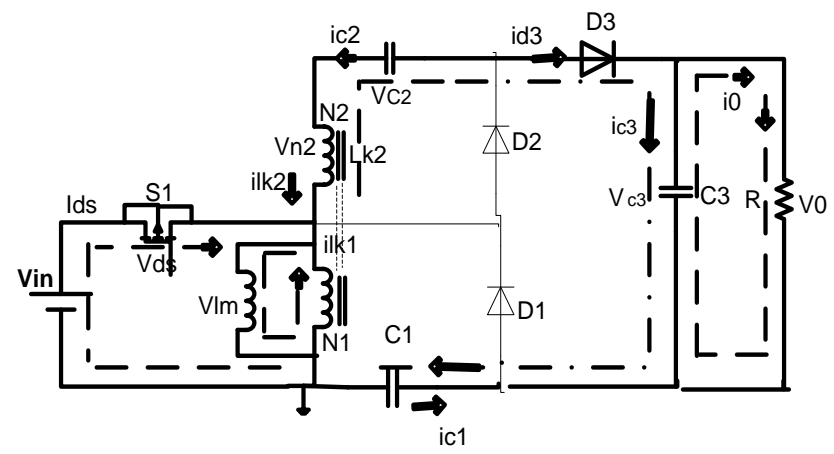

Figure 3. Circuit diagram for mode 2 operation

3) Mode 3[t $\left.\mathbf{t}_{2}, \mathbf{t}_{3}\right]$ : During this time interval, secondary inductor $L_{K 1}$ of the pair keeps charging $C_{3}$ once the switch S1 is OFF. The present flow path of current is shown in Figure 4, where the diodes $\mathrm{D}_{1}$ and $\mathrm{D}_{3}$ are conducting. The energy present in the leakage inductor $\mathrm{L}_{\mathrm{k} 1}$ flows through diode $\mathrm{D} 1$ to charge the capacitor $\mathrm{C} 1$ instantly once the switch $\mathrm{S} 1$ is OFF. Meanwhile, the energy of secondary inductor $\mathrm{L}_{\mathrm{k} 2}$ and a pair is serialy connected with $\mathrm{C}_{2}$ to charge output capacitor $\mathrm{C}_{3}$ and therefore the load. As a result of discharge, inductance $L_{k 1}$ and $L_{k 2}$ vary smaller than $L_{m}$ and $i_{l k 2}$ speedily decreases, however $i_{l m}$ increases as the magnetizing inductor is receiving energy from $\mathrm{L}_{\mathrm{k} 1}$. Current $\mathrm{i}_{\mathrm{lk} 2}$ decreases till it reaches zero and the mode ends at $\mathrm{t}=\mathrm{t}_{3}$.

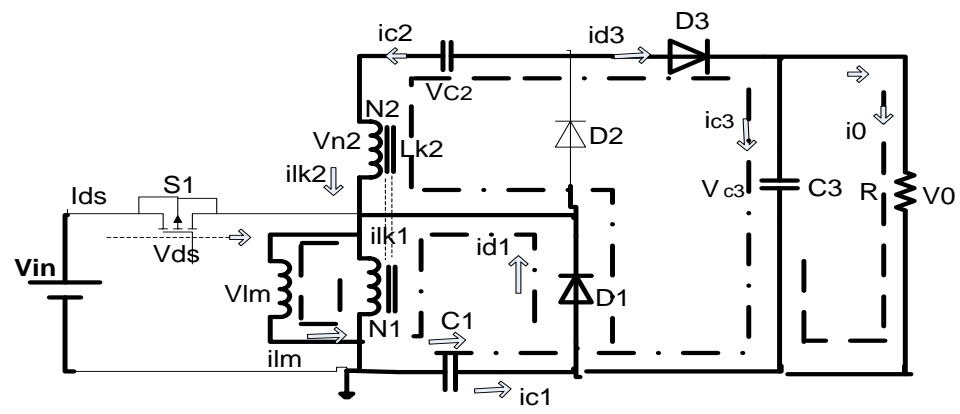

Figure 4. Circuit diagram for mode 3 operation

4) Mode 4[t $\left.\mathbf{t}_{\mathbf{4}}, \mathbf{t}_{\mathbf{5}}\right]$ : During the transition interval as shown in the Figure 5, the energy in the form of magnetizing electrical device luminous flux unit is discharged to the capacitors $\mathrm{C} 1$ and $\mathrm{C} 2$ at the same time and only the diodes D1 and D2 are conducting. Currents ic1 and iD1 is frequently bated as a result the outflow energy still flowing through diode D1 keep on charging the condenser $\mathrm{C} 1$. The energy in the form of luminous flux unit is delivering through Tonand D2 to charge the condenser C2. The energy present in the condenser $\mathrm{C} 3$ is consistently discharged to the load R. These energy transfers leads to decrease in the iLm however there will be an increase in iL mountain peak. This mode ends once current 
variety one is zero, at $\mathrm{t}=\mathrm{t} 4$.

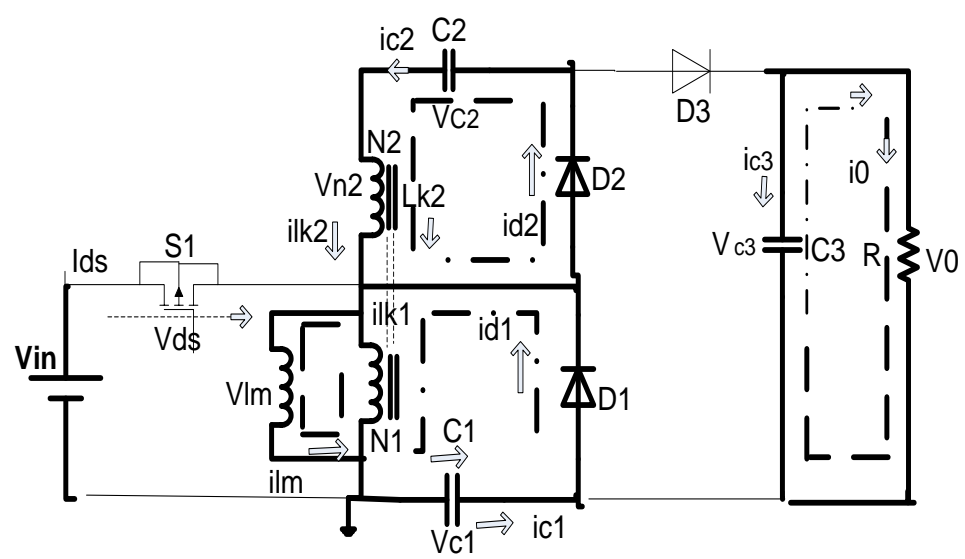

Figure 5. Circuit diagram for mode 4 operation

5) Mode 5 [t4, t5]: During this mode, theenergy from the magnetizing inductor $1 \mathrm{~m}$ is continuously transferred to the capacitor $\mathrm{C} 2$. The current flow path is shown in Figure 6, during which only diode D2 is con- ducting. The currentiLm is decreasing because of the magnetizing inductance power flowing through the coupled inductance T1 to secondary winding N2, and D2 continues to charge capacitor C2. The energy stored in the capacitor C3 is continually discharged to the load R. This mode ends once the switch $\mathrm{S} 1$ is turned $\mathrm{ON}$ at the beginning of subsequent shift period.

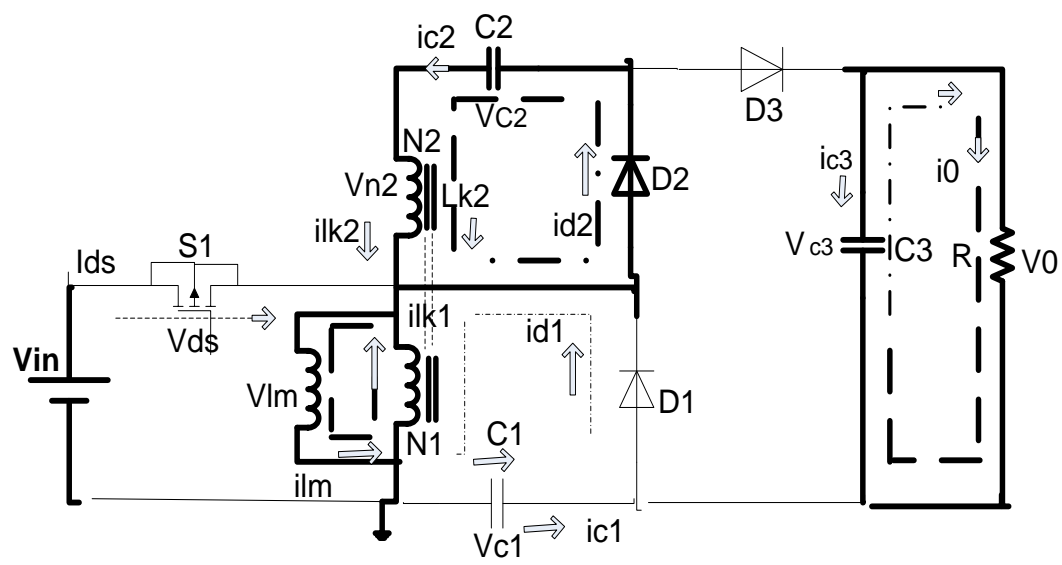

Figure 6. Circuit diagram for mode 5 operation

\section{INTERFACING OF VOLTAGE SOURCE INVERTER (VSI) TO GRID}

The Figure 7 shows the basic block diagram of the proposed VSI with a hysteresis control circuit, which is interfaced to the grid with the RES as the dc voltage source. A 4-leg Inverter (VSI) (Figure 8) along with the Active power filter [3] is used to eliminate the current harmonics and prevent the equipment from overheating. The grid interface inverter is used for Injecting the power to the grid during the unbalanced conditions where the non-linear, unbalanced load current are compensated. Here VSI will act as a Shunt Active Power Filter. As shown in the Figure 7 the DC link capacitor will be acting as an interface between the current controlled VSI (or) Grid interface inverter and RES. Here the RES is a PV system which supplies a variable power to the grid. The DC-link capacitor plays a major role in transferring the variable power to grid. A unidirectional DC/DC converter shown in the Figure 8 is used for supplying high voltage DC to grid interface inverter. So, power conditioning is needed for the RES. By power conditioning suitable DC voltage is being given the inverter whether the source is either AC/DC. Voltage source Inverter (VSI) and filter configurations are used to convert the DC voltage to AC voltage. 


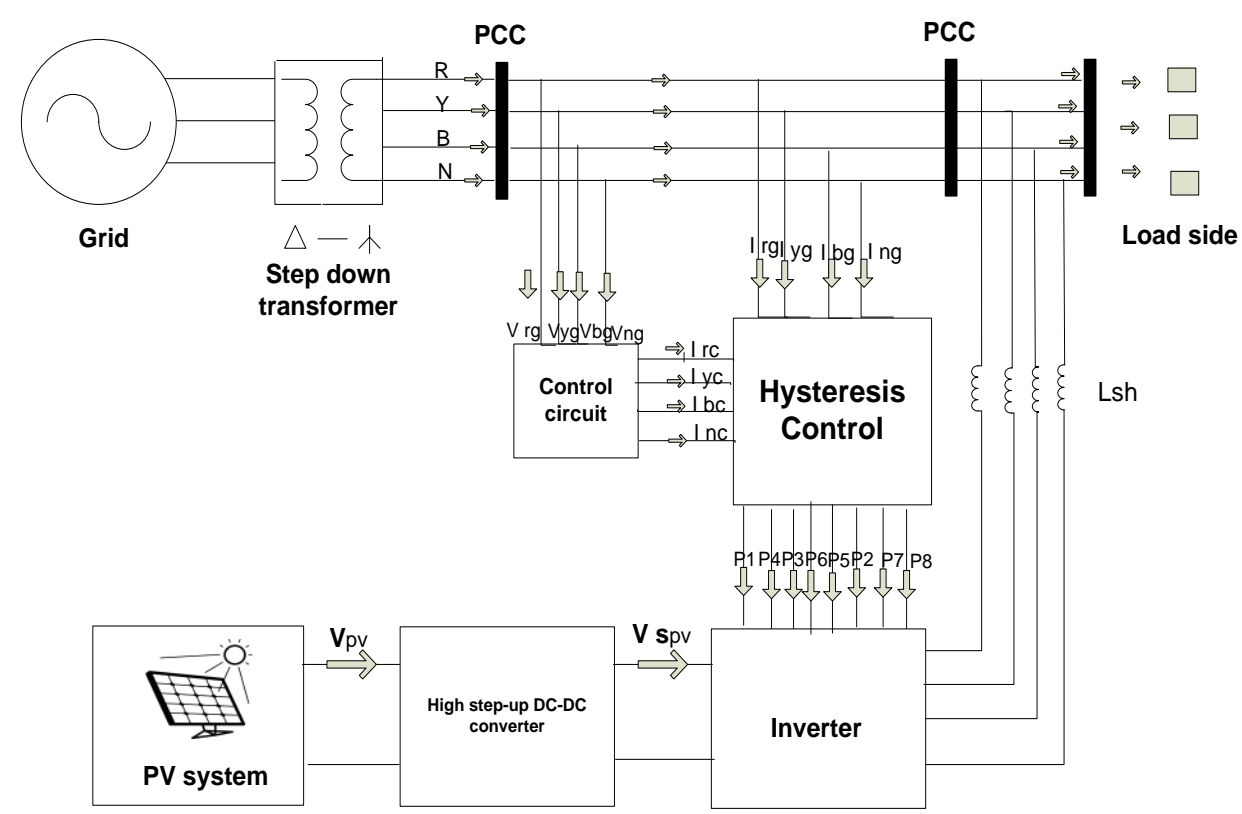

Figure 7. Proposed circuit with Renewable Energy System

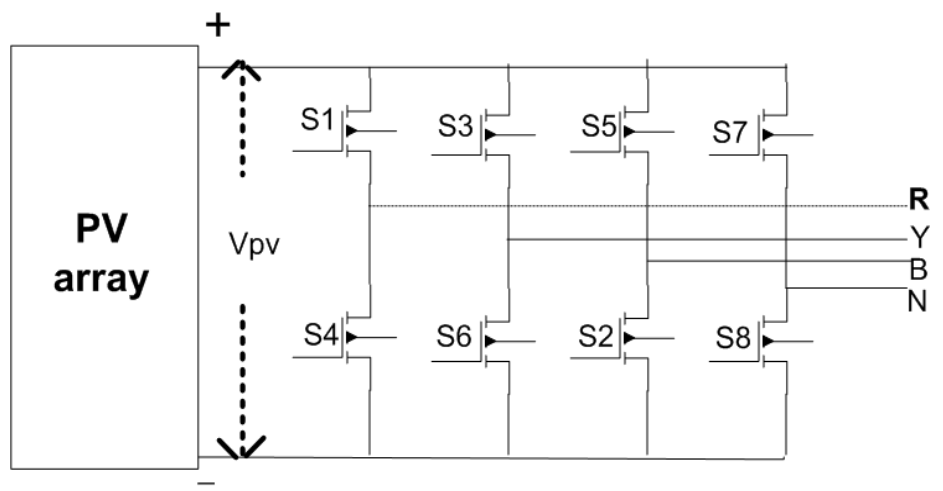

Figure 8. Grid Interfacing Inverter

The power generated by RES is variablein nature. The dc-link plays an important role in transferring the variable power from RES to grid. The current that is being injected into the dc-link is given by

$$
I_{p v 1}=\frac{P_{p v}}{V_{p v}}
$$

where, $\quad P_{p v}=$ Power generated from RES.

The current on the other side of dc-link is given by

$$
I_{p v 2}=\frac{P_{i n v}}{V_{p v}}=\frac{P_{G}+P_{\text {Loss }}}{V_{p v}}
$$

where,

$P_{i n v}=$ Power from the Grid-interfacing inverter power,

$P_{G}=$ Active power that supplied to the grid,

$P_{\text {Loss }}$ - Inverter losses.

By assuming inverter losses as negligible then, 


$$
P_{p v}=P_{G}
$$

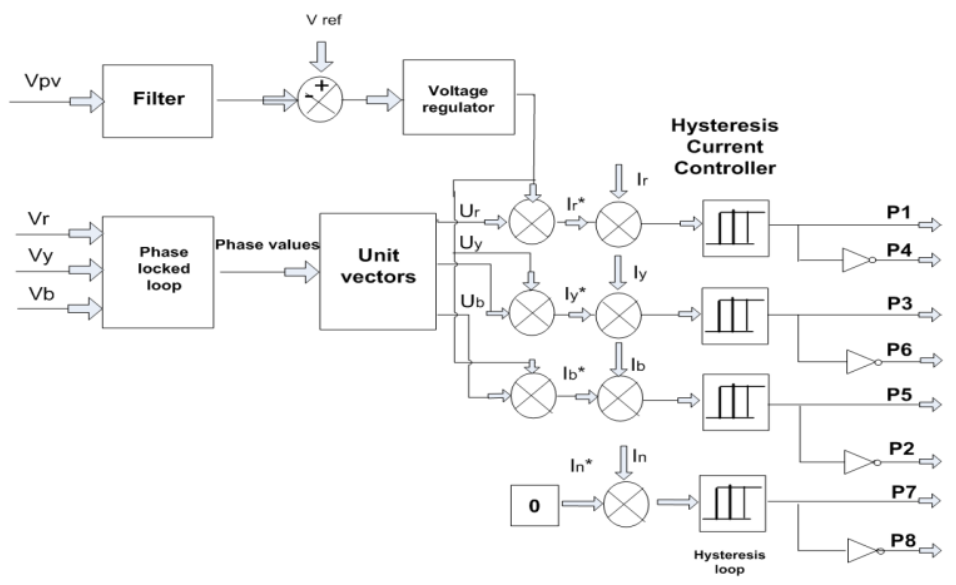

Figure 9. Block diagram representation of Control Circuit of the inverter

\section{CONTROL UNIT OF GRID INTERFACING INVERTER}

Control unit of grid interface inverter is shown in Figure 9. Here the neutral current is compensated by the four leg grid interface inverter (VSI). If unbalanced load is connected to point of common coupling, the control approach compensates the harmonic currents, unbalanced and neutral currents. By varying the duty ratios of inverters switches balanced power appears at resistive load [2] of grid. The active power flow between RES and AC grid can be realised from regulation of the dc-link voltage. Therefore, dc-link voltage output results in active current $\left(\mathrm{I}_{\mathrm{m}}\right)$ which when multiplied with unity grid voltages $\left(\mathrm{U}_{\mathrm{r}}, \mathrm{U}_{\mathrm{y}}\right.$ and $\left.\mathrm{U}_{\mathrm{b}}\right)$ generate reference grid currents $\left(\mathrm{I}_{\mathrm{r}}^{*}, \mathrm{I}_{\mathrm{y}}^{*}\right.$, and $\left.\mathrm{I}_{\mathrm{b}}^{*}\right)$. A phase lock loop (PLL) has been used to obtain grid synchronous angle $(\theta)$.

$$
\begin{aligned}
& \mathrm{U}_{\mathrm{r}}=\sin \theta \\
& \mathrm{U}_{\mathrm{y}}=\sin \left(\theta-\frac{2 \pi}{3}\right) \\
& \mathrm{U}_{\mathrm{b}}=\sin \left(\theta+\frac{2 \pi}{3}\right)
\end{aligned}
$$

where, $\left(\mathrm{U}_{\mathrm{r}}, \mathrm{U}_{\mathrm{y}}\right.$ and $\left.\mathrm{U}_{\mathrm{b}}\right)=$ Unity grid vector voltage vectors

First order Low Pass Filter (LPF) is used to eliminates the switching disturbances of dc-link voltage $\left(V_{p v}\right)$ in reference to generated current signals $\left(V_{p v}^{*}\right)$. Under the change in generating power and load varying conditions, PI discrete regulation [3] is used to maintained constant dc link voltage. The error at the dc-link voltage when compared to reference dc-link voltage $\left(V_{p v}^{*}\right)$ is given to PI controller to obtain the constant dclink voltage at RES.

The $n^{\text {th }}$ sample of PI regulator is given as

$$
\mathrm{I}_{\operatorname{loss}(\mathrm{n})}=\mathrm{I}_{\mathrm{loss}(\mathrm{n}-1)}+\mathrm{K}_{\mathrm{Pd}}\left(\mathrm{V}_{\mathrm{pve}(\mathrm{n})}-\mathrm{V}_{\mathrm{pve}(\mathrm{n}-1)}\right)+\mathrm{K}_{\mathrm{I}_{\mathrm{d}}} \mathrm{V}_{\mathrm{pve}(\mathrm{n})}
$$

where,

$K_{P d}$-Proportional gain of the PI controller. $K_{I_{d}}$ - Integral gain of the PI controller.

Thus actual values of 3-phase reference grid currents are computed as

$$
\begin{aligned}
& \mathrm{I}_{\mathrm{r}}^{*}=\mathrm{I}_{\mathrm{m}} \cdot \mathrm{U}_{\mathrm{r}} \\
& \mathrm{I}_{\mathrm{y}}^{*}=\mathrm{I}_{\mathrm{m}} \cdot \mathrm{U}_{\mathrm{y}} \\
& \mathrm{I}_{\mathrm{b}}^{*}=\mathrm{I}_{\mathrm{m}} \cdot \mathrm{U}_{\mathrm{b}}
\end{aligned}
$$

where, $\mathrm{I}_{\mathrm{r}}^{*}, \mathrm{I}_{\mathrm{y}}^{*}, \mathrm{I}_{\mathrm{b}}^{*}$. = Generating reference grid currents

As the fourth leg of the grid interface inverter compensates the neutral current, the grid neutral reference current $\left(\mathrm{I}_{\mathrm{n}}^{*}\right)$ is considered as a zero i.e., 


$$
\mathrm{I}_{\mathrm{n}}^{*}=0
$$

The error value of currents areobtained by comparing actual (actual) grid currents $\left(I_{r}^{*}, I_{y}^{*}, I_{b}^{*}\right)$ with the reference grid currents $\left(I_{r}, I_{y}, I_{b}, I_{n}\right)$ ie.,

$$
\begin{aligned}
& \mathrm{I}_{\text {rerr }}^{*}=\mathrm{I}_{\mathrm{r}}^{*}-\mathrm{I}_{\mathrm{r}} \\
& \mathrm{I}_{\text {yerr }}^{*}=\mathrm{I}_{\mathrm{y}}^{*}-\mathrm{I}_{\mathrm{y}} \\
& \mathrm{I}_{\text {berr }}^{*}=\mathrm{I}_{\mathrm{b}}^{*}-\mathrm{I}_{\mathrm{b}}
\end{aligned}
$$

The Errorbetween the actual value and the reference value of currents of the inverter gives the switching sequence of each switch of the leg of the inverter as follows

a. If $I_{r, I n v}<\left(I_{r, I n v}^{*}-h_{b}\right)$, then switch $T_{1}$ will be in OFF position $\left(P_{1}=0\right)$ and switch $T_{4}$ will be in ON position $\left(P_{4}=1\right)$ of the phase "a" leg of inverter.

b. If $I_{r, I n v}>\left(I_{r, I n v}^{*}-h_{b}\right)$, then upper switch $T_{1}$ will be ON $\left(P_{1}=0\right)$ and lower switch $T_{4}$ will be OFF $\left(P_{4}=0\right)$ in the phase "a" leg of inverter.

$h_{b}$ - Width of hysteresis band. Thus, the switching pulses for the other remaining three legs can be derived.

\section{SIMULATION RESULTS}

The voltage waveform of a high step up dc-dc converter with a closed loop control technique is shown in the below Figure 10. The voltage is being stepped up to nearly 13 times as much as the voltage is being generated by the PV panel. Only one switch is used in order to obtain high dc voltage. So that, the switching losses are reduced. This converter has high voltage gain, the efficiency is more for this converter as the duty ratios are very less for the switch. The voltage conversion ratio is high for this DC-DC converter so that the voltage stepped up is much higher compared to the input that is being generated by the panel.

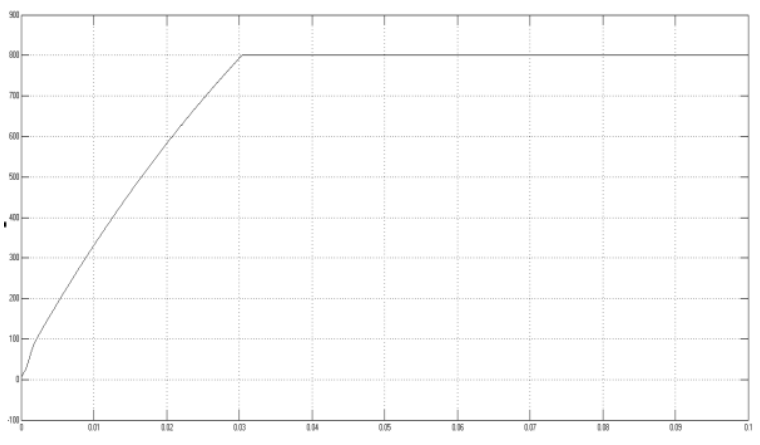

Figure 10. Output voltage of high step up dc-dc converter with PI controller (Closed Loop Control)

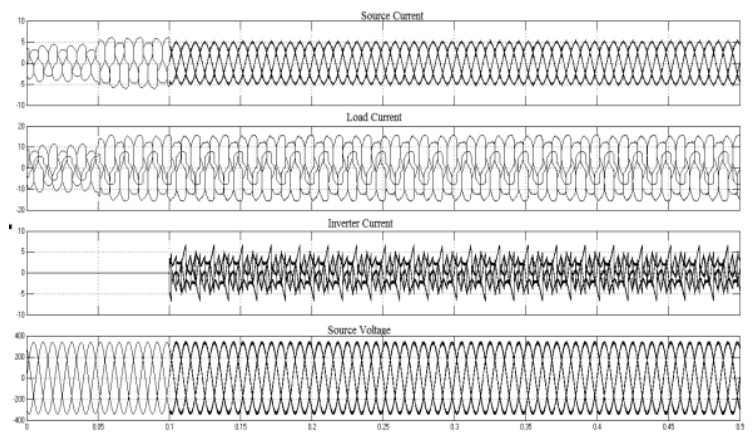

Figure 11. Source current, load current, inverter current, and source voltage waveforms of three phase system

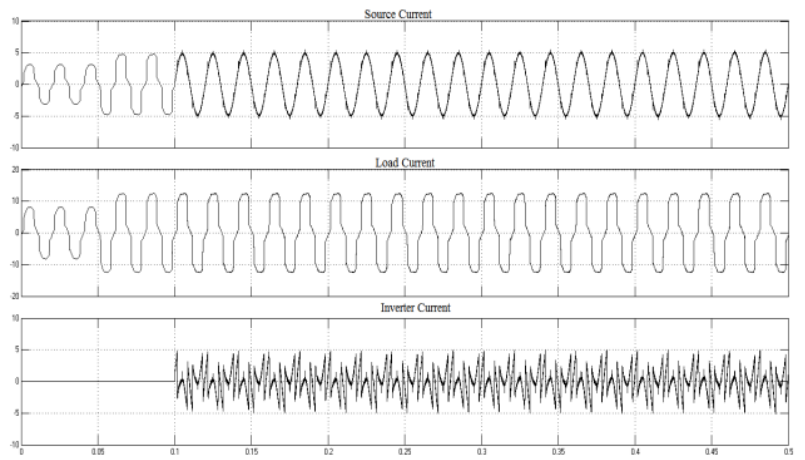

Figure 12. Current Waveforms for the Single phase system 
The above Figure 11 and Figure 12 shows the response of the system in both single phase and 3phase sources when connected to both linear and non-linear loads. Upto the transition time 0.1, the system is in non stabilized condition. After the transition time $\mathrm{T}=0.1$ ie., the inverter is being connected to the grid, the grid system is being stabilized by supplying the current to the grid as per the requirement. This is process is done according to the error values given the hystersis controller by comparing both the reference values and the sampled values (ie., both voltage and current values) from the grid. As a result the switching pulses that are being given to the converter are according to the load variations by using hysteresis current controller technique.

\section{CONCLUSION}

This paper presented the three phase four-wire inverter for grid interconnection of PV system with gird. The low voltage obtained from the PV system is enhanced by the high step up dc-dc converter with less number of components and it is also implemented in closed loop configuration to get required response. Suitable response from a DC-DC converter can be obtained with the proper selection of Kp and Ki values. Hysteresis controller generates the pulses for three phase four-wire inverter which helps in achieving a stabilized neutral current, compensated reactive power components and balanced load currents. This concept requires fewer components when compared to existing techniques like APF, hence its implementation is easy and also low cost.

\section{REFERENCES}

[1] Mukhtiar Singh, Vinod Khadkikar, Ambrish Chandraand Rajiv K. Varma, "Grid Interconnection of Renewable Energy Sources at the Distribution Level with Power-Quality Improvement Features”, IEEE Trans. power delivery, 2010 Nov, pp. 307-315.

[2] Ezhilarasan S, Palanivel P, Sambath S, "Design and Development of Energy Management System for DG Source Allocation in a Micro Grid with Energy Storage System”. Indian journal of science and Technology, 2015 Jul., 13(8).

[3] Khadkikar V, Chandra A, Barry A O, Nguyen T D, “Application of UPQC to protect a sensitive load on a polluted distribution network”, in Proc. Annu. Conf. IEEE Power Eng. Soc. Gen. Meeting, Montreal. Que. 2006, pp. 867-872.

[4] Blaabjerg F, Teodorescu R, Liserre M, Timbus A V, "Overview of control and grid synchronization for distributed power generation systems”, IEEE Trans. Ind. Electron., 2005 Oct.,53(5), pp. 1398-140.

[5] Karuppanan P, Mahapatrab K K, "PLL Synchronization with PID Controller Based on Shunt Active Power Line Conditioner", International Journal of Computer and Electrical Engineering, 2011 Feb., 3(1).

[6] Jintakosonwit P, Fujita F, Akagi H, Ogasawara S, "Implementation and performance of cooperative control of shunt active filters for harmonic damping throughout a power distribution system”, IEEE Trans. Ind. Appl., 2003 Apr., 39(2), pp. 556-564

[7] Green TC, Marks JH, "Control techniques for active power filters", IEEE proceedings of electric power applications, 2005 Mar, 152, pp. 369-381.

[8] Brahim Berbaoui, Samira Dib, Rachid Dehini, "Grid connected photovoltaic power systems and power quality improvements based on active power filter", IJECE, 2011 September, vol. 1, no 1, pp 43-48.

[9] Q. Zhao and F. C. Lee, "High-efficiency, high step-up dc-dcconverters", IEEE Trans. Power Electron, vol. 18, no. 1, pp. 65-73, Jan. 2003.

\section{BIOGRAPHIES OF AUTHORS}

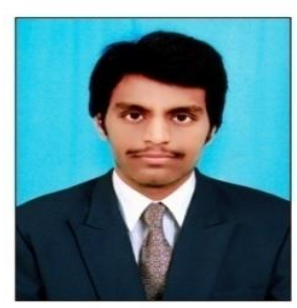

V S Prasadarao K Received the B.TECH degree in Electrical and Electronics from Lakireddy Balireddy College of engineering, Mylavaram, Krishna (DT), A.P, India, in 2011 and MTECH in power Electronics and Electrical drives from Gudlavalleru engineering college, Gudlavalleru, Krishna (DT), A.P, India in 2013 India. Currently he is working as Assistant Professor in K L University, Vaddeswaram, Guntur (DT), A.P, and India. His interested areas are in the field of renewable energies, power converters, and electrical drives. 

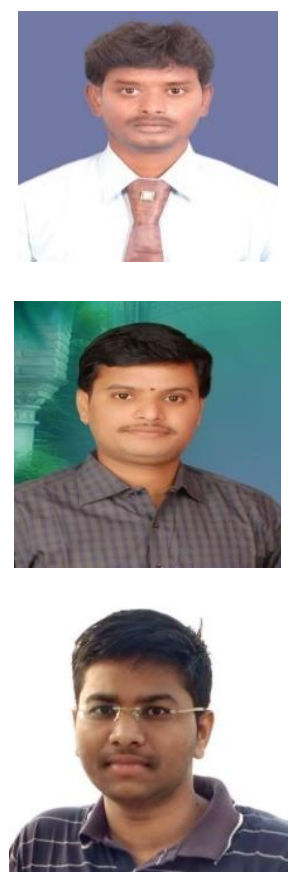

K V Krishna Rao Received the B. TECH degree in Electrical and Electronics from NIT, Bhopal, India, in 2004 and MTECH in power systems and power Electronics from K L C E, India in 2007 India, 2007 Currently he is working as Assistant Professor in JIGJIGA University, Ethiopia. His interested areas are in the field of renewable energies, power converters, and electrical drive

P Bala Koteswararao K Received the B. TECH degree in Electrical and Electronics from amara institute of engineering and technology, Narasaraopet, Guntur (DT), A.P, India, in 2011 and MTECH in power Electronics and Electrical drives from Gudlavalleru engineering college, Gudlavalleru, Krishna (DT), A.P, India in 2014 India. Currently he is working as Assistant Professor in Gudlavalleru engineering college, Krishna (DT), A.P, and India. His interested areas are in the field of electrical machines, power converters, and electrical drives

T. Abishai, presently he is pursuing B.tech in Electrical and Electronics Engineering from K L University,vaddeswarem, Guntur Dist - India. His interested areas are energy systems, DC-Dc converters and Multiinverters. 